\title{
0993. Heme oxygenase - 1 attenuates acute pulmonary inflammation by decreasing the release of segmented neutrophils from the bone marrow
}

\author{
F Konrad*', S Braun, I Vollmer, K-C Ngamsri, J Reutershan
}

From ESICM LIVES 2014

Barcelona, Spain. 27 September - 1 October 2014

\section{Introduction}

The stress response enzyme heme oxygenase 1 (HO-1) is expressed ubiquitous in the body tissue and mediates, besides its major biological function of heme degradation, a variety of anti-inflammatory effects. Although these effects have been described in various models, underlying mechanisms remain elusive. Few studies revealed an influence of $\mathrm{HO}-1$ on the bone marrow [1].

\section{Objectives}

We investigated the particular role of the bone marrow in terms of HO-1-dependent pulmonary inflammation.

\section{Methods}

Wildtype mice inhaled LPS for 30 minutes. After 24h, PMNs were detected in lung compartments (intravascular - interstitial - alveolar) using a flow cytometry-based technique. Bone marrow and blood were analyzed by flow cytometry after four hours. HO-1 was pharmacologically induced by Cobalt(III)Protoporphyrin-IX-Chloride (CoPP) and inhibited by TinProtophorphyrin-IX (SnPP). Chemokines were measured in the BAL and bone marrow by ELISA.

\section{Results}

Immunohistochemistry revealed less lung destruction after $\mathrm{HO}-1$ stimulation by $\mathrm{CoPP}$, and in vivo migration assay showed reduced PMN migration into the BAL. Differentiation of PMNs in the BAL revealed a decrease of segmented PMNs after HO-1 activation. In this group, segmented PMNs were also decreased intravascularly and concordantly, mature and immature PMN populations were higher in the bone marrow. Inhibition of HO-1 by $\mathrm{SnPP}$ aggravated parameters of tissue inflammation, led to destruction and increased PMN migration into the BAL. Differential BAL counts in this group revealed an increase of segmented and banded PMNs with enhanced PMN release from the bone marrow. The chemokine SDF-1, which mediates homing of leukocytes into the bone marrow, was increased by CoPP and reduced by inhibition of HO-1. When SDF-1 was blocked by the specific antagonist AMD3100, HO-1 activation was no longer effective in curbing PMN trafficking to the inflamed lungs. Additionally, we compared the inhibition of HO-1 by SnPP alone and in combination with CoPP. Enzyme activity was more reduced after CoPP/SnPP treatment, resulting in deteriorated lung injury with higher PMN counts in the lung interstitium, and pronounced tissue destruction.

\section{Conclusions}

We show evidence that the anti-inflammatory effects of HO-1 are largely mediated by inhibiting the release of segmented PMNs from the bone marrow rather than direct effects within the lung.

\section{Grant acknowledgment}

This work was supported by German Research Foundation Grant RE 1683/41 (to Jörg Reutershan).

Published: 26 September 2014 


\section{Reference}

1. Wegiel B, Gallo DJ, Raman KG, et al: Nitric oxide-dependent bone marrow progenitor mobilization by carbon monoxide enhances endothelial repair after vascular injury. Circulation 2010, 121:537-548.

doi:10.1186/2197-425X-2-S1-P78

Cite this article as: Konrad et al:: 0993. Heme oxygenase - 1 attenuates acute pulmonary inflammation by decreasing the release of segmented neutrophils from the bone marrow. Intensive Care Medicine Experimental 20142 (Suppl 1):P78.

\section{Submit your manuscript to a SpringerOpen ${ }^{\mathcal{O}}$ journal and benefit from:}

- Convenient online submission

- Rigorous peer review

- Immediate publication on acceptance

- Open access: articles freely available online

- High visibility within the field

- Retaining the copyright to your article

Submit your next manuscript at $\gg$ springeropen.com 